\title{
SPECIAL POWER ELECTRONICS TOPICS
}

\section{SESSION SUMMARY}

\author{
R.D. MIDDLEBROOK, Session Chairman
}

Session 2 covers a broad spectrum of topics, ranging from circuit analysis methods through new circuit configurations to system applications, and also a component testing technique.

In the first paper, Hayner et al. Introduce a new pulse-width-modulated dc-to-dc boost converter, the Venable converter, in which current is fed continuously to the output capacitor, thereby alleviating the filtering requirements. In addition, the converter has high efficiency and transfer function properties that do not depend upon the duty ratio. Rostad et al, in the second paper, describe the application of the Venable converter to a series of satellite TWT power processors.

In the third paper, by Honey et al, a neutral beam power supply system for the Lawrence Berkeley Laboratory $20 \mathrm{kV} 10 \mathrm{~A}$ sources is described. Of particular interest is the system capability to produce pulses up to $10 \mathrm{sec}$ in length. Major system features include a $1-15 \mathrm{~V}$ 1500A dc filament supply, a 60V 2000A dc arc supply, and a $0-20 \mathrm{kV} 20 \mathrm{~A}$ accel supply.

In the fourth paper, by Schwarz et al, a return to component considerations is made with a method for the calculation of an apparent time invarying inductance for an iron-cored inductor. An on-line hybrid digital-analog sampling and signal processing technique is used to determine an inductance which is equivalent to an actual non-1inear inductor operated under either continuous or discontinuous conduction conditions.

In the last paper, by Klima and Riley, an ultrasonic scanning technique is described by which circuit board materials can be evaluated for use in high voltage areas of power electronics systems. The technique arises as a consequence of an observed correlation between ultrasonic attenuation and corona inception voltage.

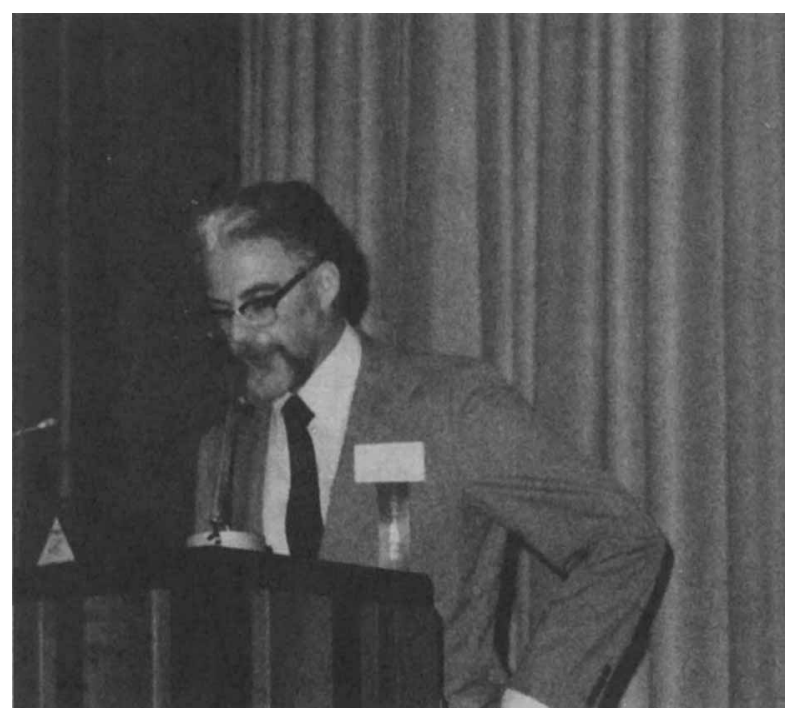

